\title{
Wide-range low-cost high precision portable piezoelectric weighing sensor system based on improved resistance strain gauges Wheatstone bridge
}

\author{
Ou Lei \\ Research Center of Sensor Technology \\ Beijing Information Science \& \\ Technology University \\ Beijing, China \\ leiou1021@163.com
}

\author{
Weijie Tian \\ Research Center of Sensor Technology \\ Beijing Information Science \& \\ Technology University \\ Beijing, China
}

\author{
Fubin chen \\ Research Center of Sensor Technology \\ Beijing Information Science \& \\ Technology University \\ Beijing, China
}

\begin{abstract}
Weighing technology is closely connected with people's life. A wide-range low-cost high precision portable piezoelectric weighing sensor system were designed for the wide weighing scale range applications based on improved resistance strain gauges Wheatstone bridge. Sensing unit, processing circuit, digital display and portable panel were studied. The modified fullbridge strain-bridge circuit which has the 8 times weighing range than typical products in the market were designed. The whole size of scale body is $0.5 \mathrm{~m} * 0.35 \mathrm{~m} * 0.02 \mathrm{~m}$. The error of weight from $0 \mathrm{~kg}$ to $8000 \mathrm{~kg}$ was no more than $15 \mathrm{~kg}$. The displayed number of display device and the weight of corresponding object showed a good linear relation. It was realizable to weight wide-range objects such as poultry with lower cost and portability.
\end{abstract}

Keywords-weighing technology; piezoelectric weighing sensor; wide-range; portability

\section{INTRODUCTION}

Weighing technology as a kind of measuring method is paid great attention by people since ancient times. It is widely used in industry and agriculture, scientific research, the transportation, the internal and external trade and other fields, and closely connected with people's life [1-3]. With the development of the modern society, the demand for weighing equipment became more heavily. The usual portable scales are lever scales which are mostly used by residents, and spring balance which measure through compression or drawing of spring. They are being rejected for their big measuring errors. People have been expecting cheap portable electronic scales which can measure accurately and be carried conveniently for many years. Electronic scales are the achievement of combination of the weighing technology and electronic technology, which has the virtue of small volume, light weight, low cost, easy maintenance, etc compared with mechanical scales, and can be widely applied to various occasions. But portable electronic scale usually has the small weighing scale range, and do not apply in many wide weighing scale range applications, for example, the large weight domestic animals trading etc.

Electronic weighing scale is composed of the weighing sensor, bearing frame, and display instrument. The wise choose of weighing sensor which is the core functional device of weighing scale is important for the designing of weighing system. According to the conversion method weighing sensor has the eight classes, such as photoelectric type, hydraulic type, the electromagnetic type, capacitance type, magnetic pole to change form, vibrating, gyro ceremony, the resistance strain type, and among them the resistance strain type is the most widely used [4-9]. Resistance strain sensor has the mature technology, low cost, moderate accuracy and scale range, and very suitable for application in household electronic scale [10$15]$.

Therefore, in this paper, wide-range low-cost high precision portable piezoelectric weighing sensor system was designed for the wide weighing scale range applications. Sensing unit, processing circuit, digital display and portable panel were studied. The modified full-bridge strain-bridge circuit which has the 8 times weighing range than typical products in the market was obtained.

\section{EXPERIMENTAL SECTION}

The pressure device is Tensile testing machine (RG T-20A, Shenzhen Reger Instrument, China). The output voltage was measured by Digital Multimeters (34461A, Keysight Technologies, USA).

\section{SYSTEM DESIGN}

The design thoughts and design points of the whole system were shown in Fig. 1. The whole system is composed of sensing unit, processing circuit, digital display and portable panel. 


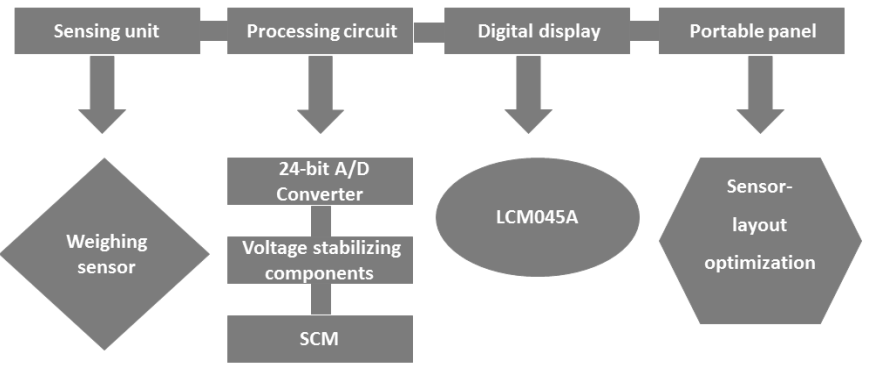

Fig. 1. Graphic design plans of Wide-range low-cost high precision portable piezoelectric weighing sensor system.

\section{A. Sensing Unit}

Wheatstone bridge [16-18] which measured the change of physical quantity through the change of the resistance is the basic foundation of weighing electronic scale. Fig. 2 shows the typical Wheatstone bridge circuit. In the Wheatstone bridge circuit, resistance strain gauge sensing weight and cause the corresponding change of the resistance value. $\mathrm{E}$ is the DC voltage source, output voltage $\mathrm{U} 0=\mathrm{UA}-\mathrm{UB}$. The resistance $\mathrm{R} 1$, $R_{2}, R_{3}$ and $R_{4}$ is the arm of bridge. When regardless of the resistance strain, if $R_{2} / R_{1}=R_{4} / R_{3}$, the output voltage of bridge $\mathrm{U}_{0}$ is as follows:

$$
\mathrm{U}_{0}=\mathrm{U}_{\mathrm{A}}-\mathrm{U}_{\mathrm{B}}=0(\mathrm{~V})
$$

The situation above is the state of equilibrium.

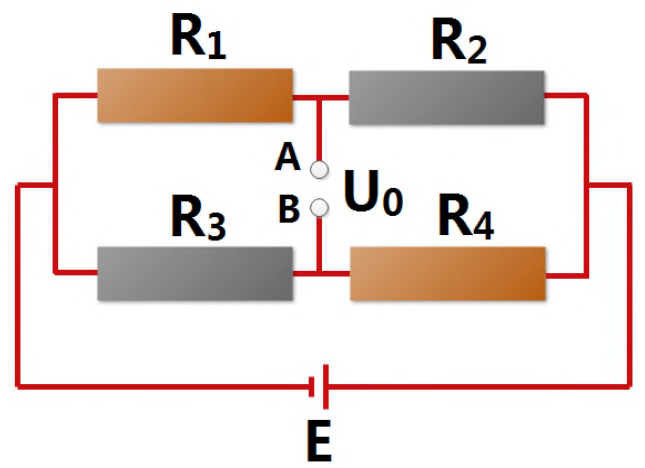

Fig. 2. The typical Wheatstone bridge.

In order to expand the range, the modified full-bridge strain-bridge circuit as shown in Fig. 3 was adopted, and the rating load was expanded by 8 times. $\triangle R$ is the increment of resistance strain gauge resistance. In the whole circuit, there are $+\triangle R$ and $-\triangle R$ due to the different location of the strain gages, and there are $\Delta R_{L}$ (variation is larger) and $\Delta R_{S}$ (variation is smaller) due to the different distance of sensor away from the centre of scale board. The output voltage $\mathrm{U}_{0}$ is as follows:

$$
\mathrm{U}_{0}=\mathrm{U}_{\mathrm{A}}-\mathrm{U}_{\mathrm{B}}=
$$

$\left(R+\Delta R_{L}+R+\Delta R_{S}\right)\left(R-\Delta R_{L}\right)\left(R-\Delta R_{S}\right)-\left(R-\Delta R_{L}+R-\Delta R_{S}\right)\left(R+\Delta R_{L}\right)\left(R+\Delta R_{S}\right)$

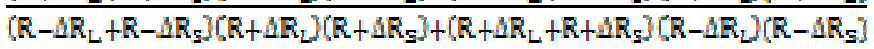

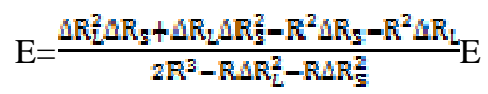

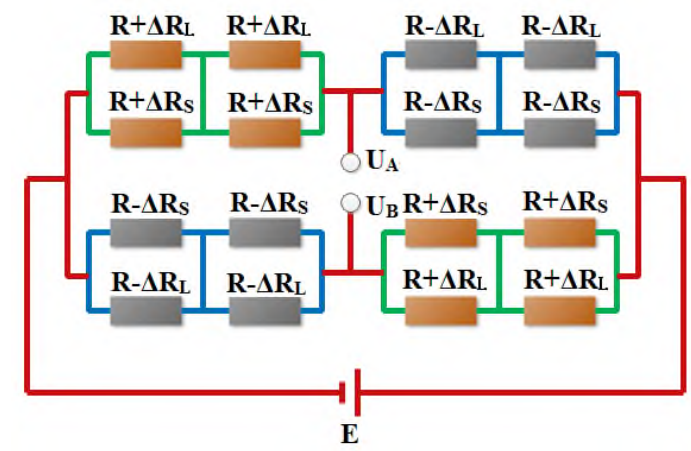

Fig. 3. The circuit connection diagram of weighing sensor.

\section{B. Processing Circuit and Digital Display}

The processing circuit and digital display were integrated into one module. The module was mainly composed of $24 \mathrm{bit}$ A/D conventor HX712, single chip STM8L101F3P6, and LCD1602 liquid crystal display.

\section{Portable Panel Design}

The whole weighing body was design as a rectangle with the size of $0.5 \mathrm{~m} * 0.35 \mathrm{~m}$. In order to even the sensing, the locating place of 8 sensors were designed as Fig. 4. The Fig. 4 (a) shows the design sketch. The Fig. 4 (b) shows the picture of real products.

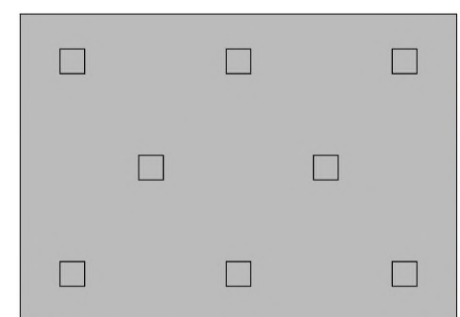

(a)

Fig. 4. The whole weighing body as a rectangle with the size of $0.5 \mathrm{~m} * 0.35 \mathrm{~m}$. (a)The design sketch. (b)The picture of real products.

\section{RESULTS AND DISCUSSION}

Fig. 5 shows the measuring range comparison of single sensor and 8 sensors. The insets are the real option of sensors. It can be seen that the measuring range of single sensor were below the $400 \mathrm{~kg}$, and 8 sensors are above $600 \mathrm{~kg}$.
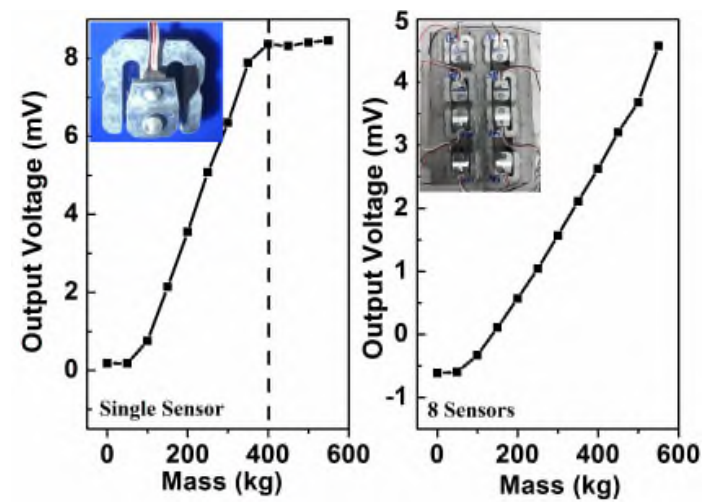

Fig. 5 The comparison of output voltage of single sensor and 8 sensors. 
In order to verify the influence of different position of scale platform on the mass results, the weighting heavy loads were put on the 4 different position with crosswise middle-pressing, lengthwise middle-pressing, crosswise left-pressing, and rightpressing, respectively, and above 10 times of experiment were taken (100 hours were taken for each experiment) for each position. Fig. 6 shows the results of crosswise middle-pressing. Fig. 6 (a) shows the pressing point and the force analysis. Fig. 6 (b) shows the relationship between the output voltage and pressure. Fig. 6 (c) shows the relationship between the mass and pressure. The 112 points were measured, and it can be seen that they show a good linear relationship. Fig. 7 shows the results of lengthwise middle-pressing. Fig. 7 (a) shows the pressing point and the force analysis. Fig. 7 (b) shows the relationship between the output voltage and pressure. Fig. 7 (c) shows the relationship between the mass and pressure. Also, the 112 points were measured, and it can be seen that they show a good linear relationship. Fig. 8 shows the results of crosswise left-pressing. Fig. 8 (a) shows the pressing point and the force analysis. Fig. 8 (b) shows the relationship between the output voltage and pressure. Fig. 8 (c) shows the relationship between the mass and pressure. The 14 points were measured, and it can be seen that they show a good linear relationship. Fig. 9 shows the results of crosswise right-pressing. Fig. 9 (a) shows the pressing point and the force analysis. Fig. 9 (b) shows the relationship between the output voltage and pressure Fig. 9 (c) shows the relationship between the mass and pressure. Also, the 14 points were measured, and it can be seen that they show a good linear relationship.

(a)
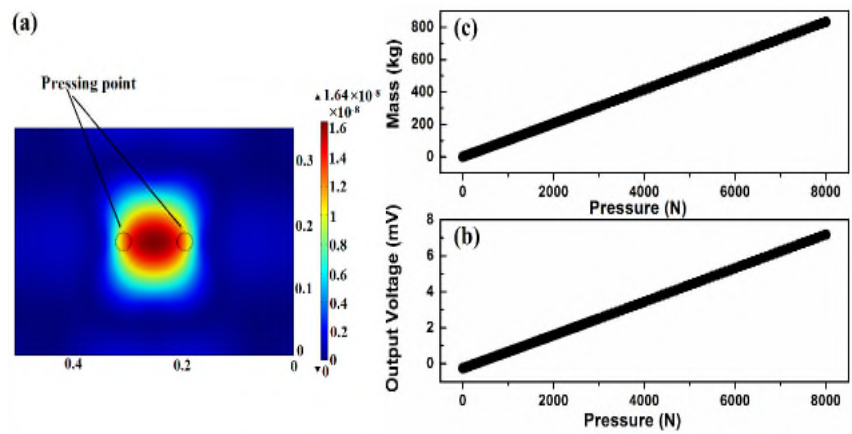

Fig. 6. The relationship between output voltage, mass and pressure with crosswise middle-pressing. (a) The pressing point and the force analysis. (b) The relationship between the output voltage and pressure. (c) The relationship between the mass and pressure.
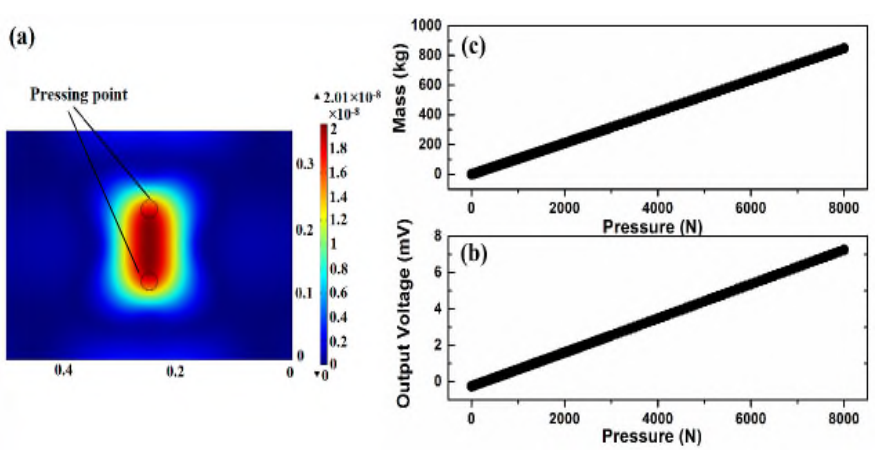

Fig. 7. The relationship between output voltage, mass and pressure with lengthwise middle-pressing. (a) The pressing point and the force analysis. (b) The relationship between the output voltage and pressure. (c) The relationship between the mass and pressure.
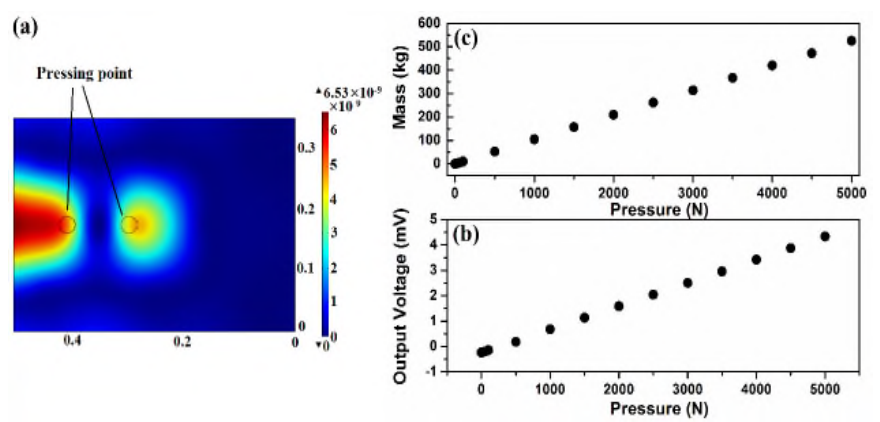

Fig. 8. The relationship between output voltage, mass and pressure with crosswise left-pressing. (a) The pressing point and the force analysis. (b) The relationship between the output voltage and pressure. (c) The relationship between the mass and pressure.
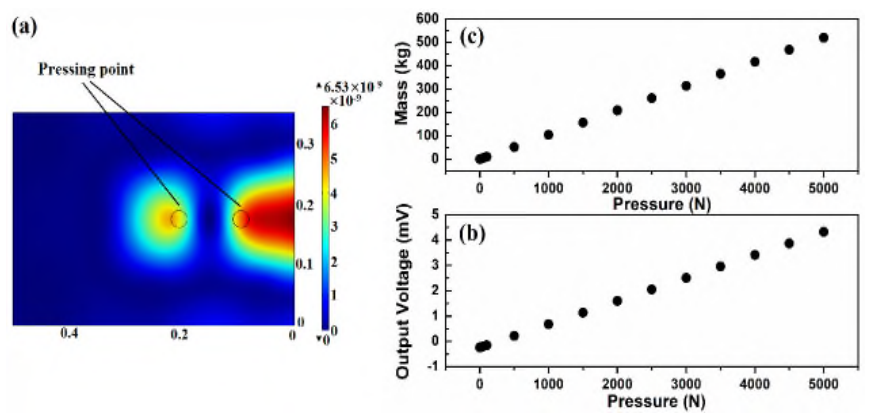

Fig. 9. The relationship between output voltage, mass and pressure with crosswise right-pressing. (a) The pressing point and the force analysis. (b) The relationship between the output voltage and pressure. (c) The relationship between the mass and pressure

The system first transformed pressure signal into electrical signal, and then output it to display device by amplification to acquire the weight of corresponding object. Through verification, the displayed number of display device and the weight of corresponding object showed a good linear relation. The error of weight from $0 \mathrm{~kg}$ to $8000 \mathrm{~kg}$ was no more than 15 $\mathrm{kg}$ so that it was realizable to weight wide-range objects such as poultry with lower cost and portability.

\section{CONCLUSIONS}

In summary, a wide-range (above $8000 \mathrm{~kg}$ ) low-cost high precision (error lower than $15 \mathrm{~kg}$ ) portable piezoelectric $(0.5 \mathrm{~m} * 0.35 \mathrm{~m} * 0.02 \mathrm{~m})$ weighing sensor system were obtained for the wide weighing scale range applications. Sensing unit, processing circuit, digital display and portable panel were designed. The displayed number of display device and the weight of corresponding object showed a good linear relation, and it was realizable to weight wide-range objects such as poultry with lower cost and portability.

\section{ACKNOWLEDGMENT}

This research was financially supported by the National Natural Science Foundation of China (60968001), Beijing Natural Science Foundation (4122030), Beijing natural science foundation of key projects (B) (KZ201511232037), Key Laboratory of Modern Measurement \& Control Technology (Beijing Information Science \& Technology University), Ministry of Education. 


\section{REFERENCES}

[1] L. Ivan, I. Damir and F. Luka. "High Value Resistance Comparison Using Modified Wheatstone Bridge Based on Current Detection". Measurement, vol. 46, pp. 4388-4393, 2013.

[2] J.H. Luo. "DSP-based design of high precision electronic scale". Comput. Meas. Contr. vol. 18, no. 8, pp. 1955-1958, 2010.

[3] Z.Y. Guo. "Design and Implementation of High-precision electronic scale based on ADS1100". J. Anhui Univ. Tech. (Nat. Sci.). vol. 24, no. 4, pp. 385-392, 2010."

[4] Y.C. Zhang and Y. Xiu. "Analysis on the Strain-Ring Structure and its Stressing of Weighing Transducer for HDS System". J. Highway Transport. Res. Develop. vol. 13, no. 4, pp. 7-11, 1996.

[5] B.J. Gao and X.P. Su. "Method of Determinating the Sensitivity Coefficient of the Resistance Strain Gauge". J. Transd. Tech. vol. 17, no. 4, pp. 49-51, 1998.

[6] C.W. Wang. "Working Principle of Weighing Sensor and Trouble Shooting”. Chem. Anal. Met. vol. 11, no. 4, pp. 40-41, 2002.

[7] J.Q. Liu. "Transverse Sensitivity and Force Compensation of Weighing Load Cell". Sci. Tech. Appl. vol. 43, no. 3, pp. 12-15, 2014.

[8] B. Xiao, Z.L. Gao. "Foreviewing the Prospects of the Electric Resistance Type Sensors from the Consideration of the Present Situation of the Electric Resistance Strain Gage”. J. North China Inst. Astronaut. Eng. vol. 10, no. 2, pp. 21-23, 2000.

[9] W. Zhao and Y.Z. Zhang. "Torque and Bending Moment in a Shaft with Combined Deformation Measured by Resistance Strain Gauge Method". J. Tangshan College. vol. 22, no. 3, pp. 1-2, 2009.

[10] B. Han. "Research on Rigid Effects of Strain Gauge". Eng. J. Wuhan Univ. vol. 2, pp. 127-133, 1993.

[11] F.Y. Yin. "Sixty years of Electric Resistance Strain Gage Technique (1)". Sens. World. vol. 8, pp. 27-32, 1998.

[12] Y.M. Lei. "Strain Transmit Research and Aberration Analysis of Electric Resistance Strain Gauge”. Sci. Tech. Eng. vol. 11, no. 32, pp. 8096-8100, 2011.

[13] L. Wang. "Application reaserch of electric resistance strain gauge in material strength experiment". Weighing Instr. vol. 44, no. 11, pp. 17-21, 2015.

[14] G.F. Qu. "Apptication of Resistance Strain Gauge in Measure the Crook Moment”. J. Transd. Tech. vol. 18, no. 4, pp. 53-54, 1999.

[15] X.G. Jiang, X.L. Yang, H. Li, L. Wen, J.S. Shi, K.Z. Zhang, J. Li and Y. Wang. "Design of high precision and high stability differential amplifying circuit for a special strain gauge". Inform. Electr. Eng. vol. 8, no. 5, pp. 573-576, 2010.

[16] G. Teodor, G. Piotr and W. Ivo. "Rangelow. Calibration and Examination of Piezoresistive Wheatstone Bridge Cantilevers for Scanning Probe Microscopy". Ultramicroscopy, vol. 97, pp. 385-389, 2003.

[17] M. De Andrea, F. Giuseppe and M. Paolo. "Analog Wheatstone Bridgebased Automatic Ineterface for Grounded and Floating Wide-range Resistive Sensors". Sens. Actuat. B: Chem. vol. 187, pp. 371-378, 2013.

[18] X.L. Wang, W.J. Wang, J.C. Wang, R. Wei, Z.X. Sun, Q. Li, C.Y. Xie, H.E. Chen, K.Q. Wang, L. Wu, Z.M. Chen and G.N. Luo. "Thermal Strain Measurement of EAST W/Cu Divertor Structure Using Electric Resistance Strain Gauges”. Fusion Eng. Des. vol. 113, pp. 1-5, 2016. 